\title{
Educação e moda na Segunda Guerra Mundial: as propagandas das campanhas da Legião Brasileira de Assistência
}

\author{
IVANA GUILHERME SIMILI*
}

\begin{abstract}
Resumo: As transformações observadas na educação e na moda, durante a participação do Brasil na Segunda Guerra Mundial (1942-1945), são examinadas à mão das propagandas das campanhas da Legião Brasileira de Assistência. Examinam-se os cartazes de quatro campanhas, para mostrar as mudanças que foram introduzidas nos comportamentos e nas atitudes das brasileiras, de modo a proporcionar a inserção e a participação feminina no conflito mundial.

Abstract: The transformations observed in the education and in fashion, during the participation of Brazil in World War II (1942-1945), are examined like the propagandas of the campaigns of the Brazilian Legion of Assistance. Are examined the posters of four campaigns, to show the changes that had been introduced in the behaviors and the attitudes of Brazilians in order to provide the insertion and the feminine participation in the world-wide conflict.
\end{abstract}

Palavras-chave: Educação. Moda. Propaganda.

Key words: Education. Fashion. Propagandas.

As campanhas políticas sempre tiveram na propaganda um poderoso instrumento e aliado na formação da opinião pública favorável aos personagens, aos projetos, aos programas envolvidos na tramas políticas. Durante o período da participação do Brasil na Segunda Guerra Mundial (1942-1945), não foi diferente. Do mesmo modo que Getúlio Vargas encontrou nas propagandas um recurso para as campanhas de mobilização dos homens, com vistas à formação dos batalhões masculinos para enviar para o campo de ba-

\footnotetext{
Doutora em História; professora da Universidade Estadual de Maringá, Paraná. O artigo apresenta resultados da pesquisa que venho desenvolvendo com o apoio do CNPq, intitulada "Educação e moda na Segunda Guerra Mundial: um estudo sobre as voluntárias da Legião Brasileira de Assistência (1942-1945)". E-mail: ivanasimili@ig.com.br
}

Estudos Ibero-Americanos. PUCRS, v. XXXIII, n. 1, p. 160-171, junho 2007 
talha, compondo o front externo de luta pela pátria, este movimento foi acompanhado por um outro, coordenado pela Legião Brasileira de Assistência (LBA). Para compor um front interno composto por mulheres dispostas a se integrar pelas causas assistenciais de guerra, a Legião Brasileira de Assistência realizou diversas campanhas, e a propaganda foi o veículo para a mobilização e o envolvimento feminino.

A Legião Brasileira de Assistência foi criada por Darcy Vargas, esposa de Getúlio Vargas, concomitante ao ingresso do país no conflito mundial, em agosto de 1942, com o objetivo de amparar os soldados mobilizados pelo conflito mundial e seus familiares. Seu surgimento foi marcado pelo estabelecimento de uma parceria entre o empresariado, o Estado e o voluntariado feminino civil, representado pelas mulheres e capitaneado pela primeiradama Darcy Vargas. Com sede fixada na capital carioca e filiais estabelecidas nas cidades brasileiras, todas administradas pelas primeiras-damas, a instituição constituiu-se no período da participação do Brasil no conflito mundial em importante centro de atuação feminina, por meio do qual o projeto assistencial foi desenvolvido.

A condução das mulheres para os quadros da Legião Brasileira e para o desenvolvimento do projeto assistencial que tinha foco nos soldados e seus familiares, foi realizada pelas campanhas desencadeadas algumas em nível nacional, outras, locais, na cidade do Rio de Janeiro, onde estava a sede. Nesse sentido, são feitas campanhas com diferentes objetivos, como, por exemplo, para a formação do voluntariado feminino com mulheres dispostas a trabalhar pelas causas assistenciais de guerra e de produtos e roupas para os soldados e seus familiares, tais como cigarros, fósforos, livros e até mesmo campanha para conseguir escritoras de cartas, as "madrinhas dos combatentes", dentre outras. Além dessas campanhas, são incorporadas pela instituição, algumas campanhas governamentais, como: a coleta da borracha usada, a Horta da Vitória, evidenciando os laços da instituição com o governo, auxiliando-o nas estratégias empregadas para contornar os problemas de alimentação e de matérias-primas na produção bélica .

Mapear as campanhas da Legião Brasileira de Assistência transforma-se numa tarefa difícil, dada a variedade de tipos, formas de condução e de divulgação. No entanto, os materiais de propaganda das campanhas que deixaram registros têm muito a contar e dizer sobre os mecanismos criados pela instituição para o envolvimento feminino nas questões e causas de guerra. Sobre esse material recai nossa análise. 
Examinam-se quatro cartazes, cuja seleção deve-se a registros na documentação consultada: o primeiro foi usado na mobilização feminina para a formação do quadro de voluntárias; o segundo é o cartaz da Horta da Vitória, que foi assinado por Cândido Portinari e almejava a colaboração feminina na produção de alimentos - hortaliças, legumes etc.; o terceiro e o quarto são respectivamente, o cartaz do "Livro do Combatente" e o da "Madrinha do Combatente", este último timbrado pelo Departamento de Imprensa e Propaganda (DIP); sendo que a campanha do livro foi desenvolvida com o objetivo da obtenção de obras literárias, históricas e outras para a criação da Biblioteca do Soldado e com a Madrinha, pretendia-se que mulheres se dispusessem a trocar correspondências com os soldados durante a permanência deles no front de guerra.

Como materiais de propaganda de guerra para a mobilização das mulheres, esses cartazes permitem múltiplas leituras e interpretações. O encaminhamento aqui adotado será o de considerá-los como artefatos pedagógicos e culturais que informam acerca das mudanças introduzidas na educação e na moda. Ao considerá-los como artefatos pedagógicos, a análise compartilha dos conceitos existentes nas tendências dos estudos da educação que consideram a propaganda como uma pedagogia cultural que ensina e transmite noções sobre modos de ser, comportar-se, agir que educam os sujeitos (Sabat, 2003, p. 149). Esse tipo de abordagem faz das propagandas, dos artefatos pedagógicos e de moda, porque moda quer dizer e tem ligação com "modo", "maneira" (Palomino, 2003, p. 15).

Como materiais de propaganda e artefatos de educação e de moda, por intermédio dos cartazes, é possível captar as noções, os comportamentos, as atitudes que foram criadas e introduzidas no universo feminino, mobilizando e levando as mulheres a aderir às solicitações e demandas institucionais; portanto, nos cartazes, estão os ensinamentos sobre moda - os modos e as maneiras que são criados pelo e para o feminino na guerra.

\section{"Trabalhe pela Vitória do Brasil"}

A primeira campanha desencadeada pela Legião Brasileira de Assistência teve neste cartaz-propaganda o artefato de comunicação entre a instituição e as mulheres. Veiculado na imprensa carioca, por intermédio do cartaz pretendia-se transformar as mulheres em voluntárias da instituição. "Trabalhe pela Vitória do Brasil", inscrevendo-se nos postos instalados na capital carioca. Mais que 
uma frase de impacto, desenha-se para as mulheres uma forma de luta e de participação na guerra: o trabalho voluntário.

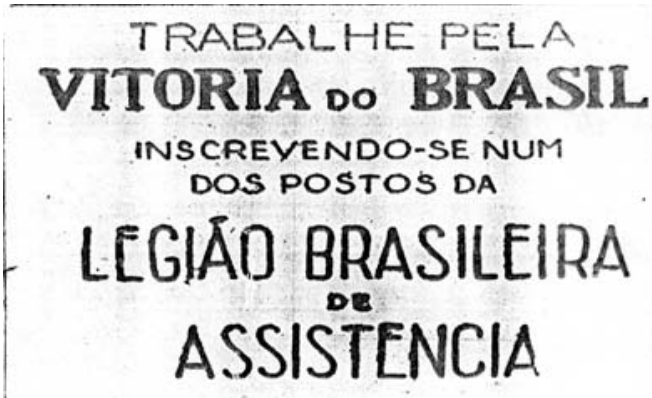

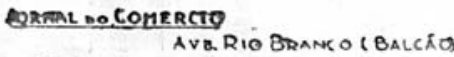

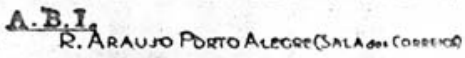

PALACE Hotel Insericio, 14 is 17 . Hona.

$\mathrm{O}$ cartaz adquire outros contornos quando se considera a movimentação masculina, ou seja, a mobilização em curso, em setembro de 1942, com o objetivo de compor os quadros com homens dispostos a partir para o front de guerra. Nas palavras de ordem que são disseminadas, principalmente pela imprensa, endereçadas às mulheres, entrevê-se que a participação masculina foi solicitada junto com a feminina, tomando parte de um processo conjunto. Afirmava-se que naquela "tremenda conflagração mundial", a Segunda Guerra Mundial, a mulher brasileira teria mais uma vez sua oportunidade para trabalhar "pelo engrandecimento de nossas forças, para o encorajamento dos que talvez tenham de seguir para as linhas de frente, na defesa da Pátria e das instituições livres do mundo". "As mulheres do Brasil", "as nobres filhas deste grande país", tinham um papel a cumprir na guerra, que era o de fazer sacrifícios em nome da Pátria, cedendo seus pais, seus filhos, seus maridos, seus noivos e, ainda, disponibilizando-se para trabalhar pela "Vitória do País", na Legião Brasileira de Assistência (Correio da Manhã, set. 1942).

Por isso, no lema da campanha, percebe-se os modos pelos quais as idéias e os conceitos patrióticos da união de esforços e de cooperação entre os sexos foram sutilmente articulados para conseguir a colaboração feminina em prol das causas do país e das mudanças que se processam no período no sentido de ensinar e desenhar às mulheres um papel a desempenhar durante o conflito mundial que era o de ficar na Pátria, aguardando o retorno dos homens, porém, tal qual os homens, trabalhando pela Pátria, por sua vitória, no campo de batalha.

A propaganda endereçada às mulheres surtiu efeitos porque milhares delas passaram a compor o batalhão feminino da LBA. Elas se alistaram no Serviço de Costura, elas foram freqüentar os cursos que são criados visando à preparação feminina, fazendo 
surgir várias espécies de voluntárias: da Defesa Passiva-Antiaérea, da Alimentação, as Samaritanas Socorristas, as Auxiliares e Visitadoras sociais e as Educadoras sociais. ${ }^{1}$

Pode-se afirmar que trabalhar na e para a instituição transformou-se numa das modas da moda de guerra, criadas pelas e para as mulheres, conduzindo condutas, comportamentos e formas de atuação e de participação.

\section{A "Horta da Vitória" de Portinari e os Jardins das mulheres}

Outra campanha da Legião Brasileira de Assistência foi a da Horta da Vitória, realizada com o nítido objetivo de apoio ao governo na solução dos problemas com a alimentação, atribuídos à guerra. Os argumentos de dificuldades na produção e no transporte de alimentos e na obtenção de matérias-primas industriais, tais como a borracha, levaram o governo a adotar algumas medidas visando à mobilização da população para ajudá-lo na solução dos problemas atribuídos à guerra. ${ }^{2}$ A realização das campanhas da Horta da Vitória e da Borracha Usada foram atribuídas à LBA.

O cartaz usado na propaganda da campanha da Horta da Vitória, foi criado por Cândido Portinari, o qual foi publicado na capa da revista Sombra, em novembro de 1942 Na composição do pintor, o "V" da Vitória ocupa o primeiro plano da imagem e no segundo ficam as plantações. A propaganda da Horta da Vitória pretendia que diante dos problemas de escassez de alimentos, as mulheres cooperassem com práticas de plantio e de cultivo de alimentos. Portanto, a intenção da campanha era transformar as mulheres participantes da luta coletiva pela Vitória, por meio da produção de alimentos em casa, nos quintais.

1 Nos limites deste texto, não será possível abordar a variedade de cursos e serviços criados pela Legião Brasileira de Assistência. Sobre o assunto ver: Simili, Ivana Guilherme. Mulher e política: a trajetória da primeira-dama Darcy Vargas (1930-19450). Assis: UNESP, 2004 (tese de doutorado).

2 O tema da mobilização da população desencadeada pelo governo Vargas no período da guerra, na cidade de São Paulo, incluindo a alimentação, foi explorado por Cytrynowicz, Roney. Guerra sem Guerra: a mobilização e o cotidiano em São Paulo durante a Segunda Guerra Mundial. São Paulo: EDUSP, 2000. 


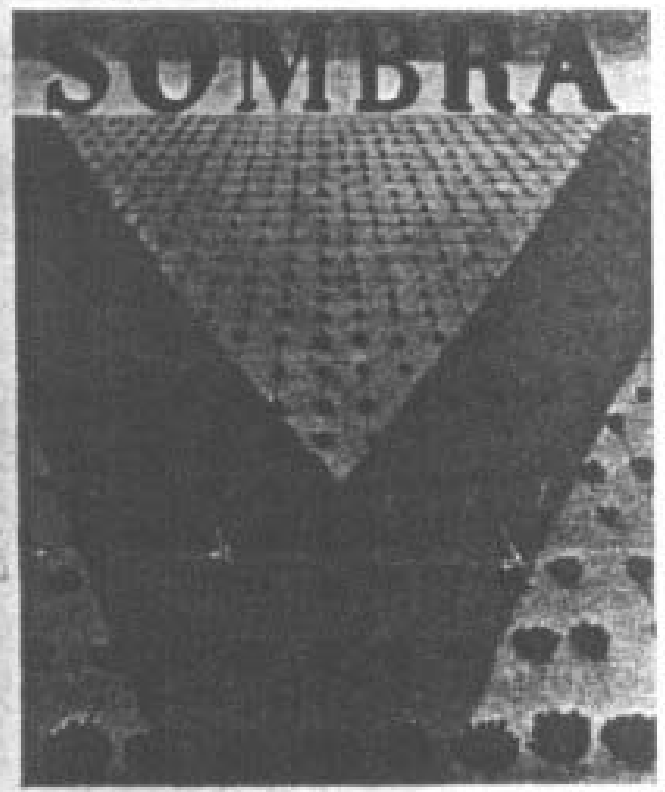

A Horta da Vitória, como fó imagina-
da pelo pincel de Candido Portioari

Os mecanismos criados para a mobilização das mulheres na campanha da Horta da Vitória podem ser dimensionados na publicação pela revista $O$ Cruzeiro de 17 de outubro de 1942, de uma matéria de moda. Intitulada "Jardins da Vitória", a matéria propunha-se a apresentar versões de roupas apropriadas para as mulheres usarem no cultivo de hortaliças e dos legumes nos seus quintais. Dizia: “'Uma horta em cada quintal' é o lema de guerra para as donas de casa, que também devemos adotar"; e o argumento norteador da campanha é assim retomado: "A dificuldade nos transportes deixa as cidades com menos verduras e frutas do que habitualmente se necessita e as vitaminas são indispensáveis". Com essa explicação, a matéria informava que "mesmo plantando a sua horta, a leitora deve procurar seis modelos realmente encan- 
tadores que publicamos nas presentes páginas que dedicamos aos 'Jardins da Vitória', onde devem medrar pepinos, cenouras, alfaces, xuxús (sic), couves e tomates".

A matéria de $O$ Cruzeiro pode ser comentada recorrendo às reflexões de Ruth Joffily (1991, p. 95), que identificou no jornalismo de moda três tipos de matérias: tendência, serviço e comportamento; cada uma correspondendo a um enfoque tanto do texto quanto da foto ou ilustração. Entretanto, na maioria das vezes, esses três tipos de matéria se apresentariam misturadas, porque a tendência é uma abordagem do que estará sendo usado na estação seguinte; o serviço informaria como a leitora deve colocar a tendência na prática, adaptando às suas necessidades, e, finalmente, o comportamento seria o tipo mais difícil de ser definido, interessando a um público maior do que aquele consumidor de moda, porque pautado pela inserção da moda na atualidade, nas correntes sociais e culturais, resgatando a moda como uma dessas correntes, com sua história, preocupação estética e simetria com os fatos.

Nas roupas da Horta da Vitória, da revista O Cruzeiro se faz presente a mistura desses elementos: tendência, serviço e comportamento. Trata-se de matéria que pretendia informar as leitoras sobre uma das tendências de roupa criadas pela guerra, oferecendo opções de emprego e formas de uso, constituindo-se numa espécie de serviço prestado às mulheres e à nação, em razão das necessidades inauguradas pelo conflito mundial e que estava desenhando novas atribuições e roupas para o feminino.

Dessa forma, por meio de cartazes de propaganda e da criação e veiculação de moda de roupas conceituadas como apropriadas ao uso no plantio, campanhas como a da Horta da Vitória ensinavam às mulheres modos de ser e de participar da luta pela vitória na guerra. No caso, era plantando e vestindo-se apropriadamente para aquela que era uma das tarefas da mulher no conflito mundial. Percebe-se, claramente, como as transformações e/ou os momentos políticos são produtores de educação e de moda, transmitindo novas noções, e, com elas, maneira de compor o visual para evidenciar a participação.

\section{Os "livros para os combatentes"}

Outra campanha da Legião Brasileira de Assistência legada pela documentação foi realizada com o objetivo de levar as mulheres a empenhar-se para a obtenção de livros para os combatentes, com vistas à produção de uma biblioteca para os soldados. As fotografias 
transformaram-se, sem dúvida, na principal fonte de informação acerca dessa campanha, pois muitas apresentam aspectos de como as mulheres foram mobilizadas e envolvidas na campanha.

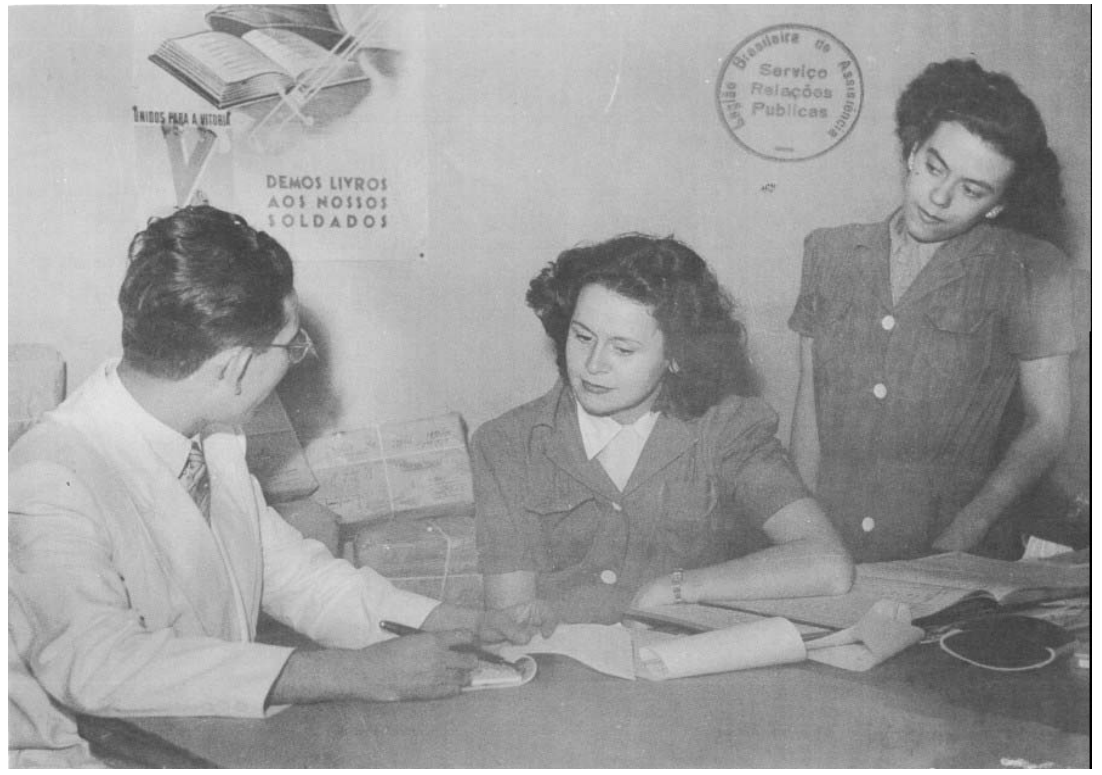

Numa das fotografias, está a imagem do cartaz que foi usado na campanha. Parte dele aparece estampado do lado esquerdo da parede, em segundo plano, e nele se lê: "Unidos para a Vitória Demos livros aos nossos soldados", colocado no cartaz no canto de baixo e na parte central vê-se um livro aberto. Novamente o "V" da Vitória é invocado para chamar e expressar o trabalho da instituição e das mulheres na guerra. ${ }^{3} \mathrm{Na}$ fotografia, os elementos que a compõem reafirmam a participação e a contribuição feminina na campanha. $\mathrm{O}$ cartaz na parede, as figuras femininas que compõem a imagem juntamente com a presença masculina e os pacotes ao fundo são elementos que visam reafirmar a cooperação feminina nas causas dos homens - a guerra e seus soldados -, visto que é a postura da figura masculina que comanda a ação na fotografia.

A maneira pela qual a campanha do livro do combatente ressoou nas mulheres, levando-as a participar do trabalho de coleta de livros, numa nítida demonstração de que a cooperação delas no alimento espiritual dos homens por meio da leitura passou a ser

3 A fotografia pertence ao acervo do CREAS, Centro de Referência da Assistência Social, no Rio de Janeiro. 
concebida como necessária e importante, pode ser avaliada pelos números divulgados pela Legião Brasileira de Assistência de que cerca de 45 mil volumes foram coletados e, após selecionados, passaram a constituir as bibliotecas ambulantes (Matos, 1945). Foram organizadas sob a forma de caixas-estantes, com aproximadamente 50 livros de vários gêneros: romances, em sua maioria de história, geografia, viagens, biografia, ciências, a biblioteca circulou pelos quartéis onde os soldados estavam aquartelados aguardando o embarque para o campo de batalha, o que aconteceu em maio de 1994 e, posteriormente, acompanhou os soldados no front de guerra.

No trabalho feminino de coleta dos livros e organização da Biblioteca, entrevê-se os modos pelos quais o espírito de doação das mulheres foi explorado pela guerra. Nesse sentido, vale lembrar que historicamente e culturalmente as mulheres foram concebidas pelos homens como portadoras de determinadas habilidades e sentimentos, e um deles era o de doação ao próximo. Na guerra, esse próximo transforma-se nos soldados e suas necessidades, e nos livros e na biblioteca as mulheres significam a doação feminina, sob a forma de alimento espiritual para a alma masculina, para aliviar a tensão que antecedeu a partida e a permanência no front de guerra.

\section{"As madrinhas dos combatentes"}

A campanha da madrinha do combatente se aproxima em muitos aspectos da biblioteca do soldado, porque se a leitura foi concebida como alimento espiritual aos soldados, oferecido pelas mulheres no trabalho de constituição e organização da biblioteca, a escrita de cartas também o foi. A campanha tinha por objetivo conseguir o maior número de mulheres dispostas a se transformarem em "Madrinhas dos combatentes", para com os soldados se comunicarem por intermédio de cartas, com vistas a levar conforto espiritual e saber de suas necessidades no front de guerra. O cartazpropaganda é bastante esclarecedor da imagem que foi produzida para conseguir a adesão feminina:

No cartaz, texto e imagem se justapõem e se completam. ${ }^{4}$ Timbrado pelo Departamento de Imprensa e Propaganda (DIP), órgão criado em 1939, por Getúlio Vargas, e responsável pela pro-

4 A imagem do cartaz-propaganda faz parte do acervo de memória da Legião Brasileira de Assistência, veiculado nos Boletins da instituição e nas obras produzidas acerca do trabalho assistencial. 


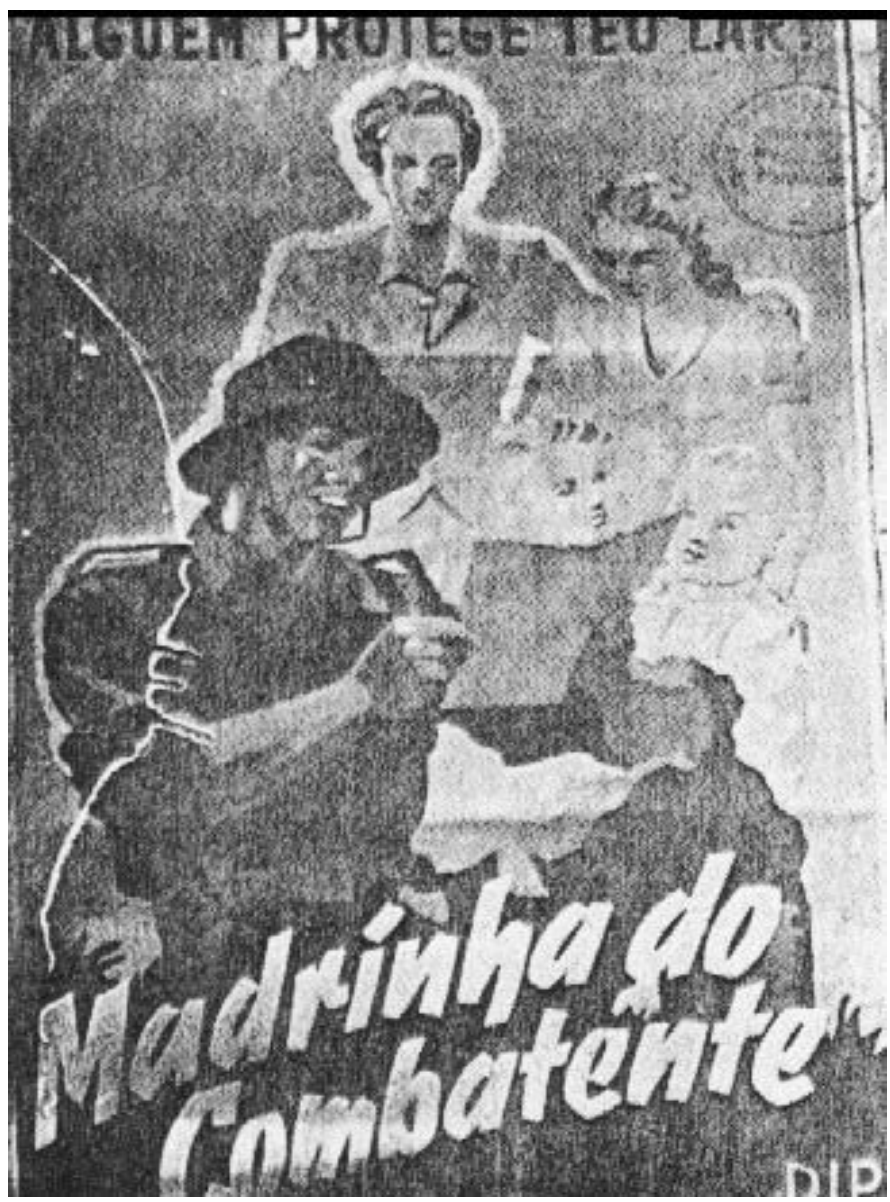

paganda política no país, o cartaz traz no primeiro plano um soldado lendo uma carta, tendo ao fundo duas figuras femininas, uma delas, central, abraçada a uma mulher que tem, abaixo de si, duas crianças, com a seguinte frase "alguém protege teu lar" (Boletim da $L B A$, fevereiro de 1945). Na sua composição, por meio da figura central, alude-se ao trabalho desenvolvido pela primeiradama e as mulheres da Legião Brasileira de Assistência, de "amparo e proteção dos soldados e seus familiares".

O que o cartaz-propaganda, indica é o trabalho de intermediação da comunicação entre as famílias e os soldados, realizado pela Legião Brasileira de Assistência, que teve na madrinha do combatente um poderoso instrumento. Por intermédio de cartas que eram escritas pelas madrinhas estabelecia-se a comunicação 
entre os familiares e os soldados, porque era papel delas obter notícias da família daqueles que estavam no front e enviar notícias, bem como atender a outros tipos de demandas dos soldados, inclusive do que lhes faltava em termos de objetos e produtos.

Os informes publicados pela instituição nos Boletins, que acompanharam o cartaz-propaganda revelam o tom de que se revestiu a campanha: "Ainda pagão? Mande uma carta à LBA e logo arranjará madrinha de guerra"; outros advertiam as madrinhas e os soldados: "Tanto as 'madrinhas' como os 'afilhados' têm obrigações recíprocas. Não é justo, pois, que vocês deixem de responder às cartas das madrinhas".

O número de madrinhas conquistadas pela Legião Brasileira de Assistência é difícil de ser dimensionado. No entanto, as notícias publicadas acerca do assunto nos boletins permitem afirmar que centenas delas aceitaram o papel de madrinhas, portanto, de escritoras de cartas.

A existência de madrinhas dos e para os soldados, conseguidas junto às camadas da elite, parece ter sido um dos fenômenos da moda na Segunda Guerra Mundial. Nesse sentido, encaminha-se a narrativa de François Baudot (2002, p. 106), ao analisar a realidade francesa: “Estação 1939-1940. Nos bastidores, a 'absurda guerra' não impede as atividades da alta costura de perpetuar-se, mesmo que entre as clientes, muitas sejam madrinhas de guerra (mulheres empenhadas em animar os combatentes, com cartas e presentes)".

As madrinhas dos combatentes da Legião Brasileira de Assistência, com seus afilhados, cartas e notícias transformam-se em emblemáticas das mudanças introduzidas pela guerra nas concepções e práticas femininas acerca daquilo que podiam fazer e realizar para os soldados, e que foi marcado principalmente pela participação de mulheres de vários segmentos sociais e faixas etárias, porque os Boletins da instituição mostram garotas, jovens e senhoras transformadas em madrinhas, revelando assim que o importante era deter o domínio da escrita e dispor-se a gastar parte do tempo para escrever, de modo a amparar os soldados no front com palavras de conforto e apoio.

Por intermédio dos cartazes usados nas propagandas de algumas campanhas da Legião Brasileira de Assistência foi possível redimensionar o papel da Segunda Guerra Mundial nas transformações na educação e na moda feminina.

Vê-se, claramente, pelos cartazes, os mecanismos criados pela Legião Brasileira de Assistência, em função da guerra, para a participação feminina e que teve nos ideais de cooperação, no conceito de luta pela vitória do país, os ingredientes para o surgimento de 
novos comportamentos, novas atitudes e condutas femininas. Inseridas na luta, na Legião Brasileira de Assistência, em nome da guerra, as mulheres aprenderam que o conflito mundial é uma questão de gênero, que envolve tanto o masculino quanto o feminino, e que para ambos significa o aprendizado.

Este aprendizado, relacionado às mulheres, pode ser vislumbrado e dimensionado de forma polissêmica, na participação que elas tiveram na instituição e nas campanhas; na adoção de posturas de cooperação e nas atitudes de doação, quer plantando em casa, angariando livros ou escrevendo cartas para os soldados.

Pode-se dizer que a guerra transformou os conceitos e os comportamentos das mulheres que participaram da guerra, por meio da Legião Brasileira de Assistência, e é nesse sentido que os cartazes indicam, e foram suas pistas que seguimos neste artigo.

\section{Referências bibliográficas}

Baudot, François. Moda do Século. São Paulo: Cosac Naify, 2002.

Boletim da Legião Brasileira de Assistência, fevereiro de1945.

Cytrynowicz, Roney. Guerra sem Guerra - a mobilização e o cotidiano em São Paulo durante a Segunda Guerra Mundial. São Paulo: Geração Editorial/EDUSP, 2000.

Joffily, Ruth. O jornalismo e produção de moda. Rio de Janeiro: Nova Fronteira, 1991.

Jardins da Vitória. O cruzeiro, ano XVI, n. 51, p.64-65, 17 de outubro de 1942.

Matos, Lobivar. A Legião Brasileira de Assistência e os soldados do Brasil. Rio de Janeiro: Legião Brasileira de Assistência, 1945.

Palomino, Érica. A moda. São Paulo: Publifolha, 2003.

Sabat, Ruth. Gênero e Sexualidade para consumo. In: Louro, Guacira; Neckel, Jane Felipe; Goellner, Silvana Vilodre (orgs.). Corpo, gênero e sexualidade: um debate contemporâneo na educação. Petrópolis: Vozes, 2003, p. 149-159.

Simili, Ivana Guilherme. Mulher e política: a trajetória da primeira-dama Darcy Vargas (1930-1945). Assis: UNESP, 2004 (tese de doutorado).

Sombra, ano 12, n. 2, novembro de 1942. 